\title{
Effects of Stabilizing Agents on Film Properties in Ag Electroless Plating
}

\author{
Hyo-Chol Koo* and Jae Jeong Kim**, \\ Research Center for Energy Conversion and Storage, School of Chemical and Biological Engineering, \\ College of Engineering, Seoul National University, Kwanak-gu, Seoul 151-742, Korea
}

\begin{abstract}
The material properties of Ag electroless deposited films with the addition of stabilizing agents were analyzed. The resistivity of Ag film was significantly increased by the addition of benzotriazole to the electroless plating solution. The high resistivity of the Ag film dramatically decreased after annealing at relatively low temperatures. Auger electron spectroscopy and X-ray diffraction analysis showed that a contribution to the high resistivity of the Ag film with benzotriazole might be from the high reflection of the electron transfer at the grain boundary. In contrast, the addition of 5-aminotetrazole did not significantly increase the resistivity, and a smooth and continuous film was obtained. In this research, a model of the film-structure formation on the Pd-activated substrate in Ag electroless plating is proposed, and a reason for the formation of a highly resistive Ag film is suggested. (c) 2008 The Electrochemical Society. [DOI: 10.1149/1.2823740] All rights reserved.
\end{abstract}

Manuscript submitted April 8, 2007; revised manuscript received October 31, 2007. Available electronically January 2, 2008.

In the recent advancements made to ultralarge-scale integration chips, new processes and materials have been adopted and applied to decrease resistance-capacitance delay. $\mathrm{Cu}$ electroplating and chemical mechanical polishing were first suggested by IBM in fullchip scale, ${ }^{1}$ and currently electroless plating is expected to be used for main conduction lines, ${ }^{2-5}$ seed layers for electroplating, ${ }^{6-8}$ barrier layers, ${ }^{9-11}$ and capping layers. ${ }^{12-15}$ Electroless plating has many advantages such as excellent uniformity on large substrates, low deposition temperature, good conformal morphology, and selective deposition. In the case of $\mathrm{Ag}$ electroless plating, some research has examined applications in metal-conducting line processing. ${ }^{16-19}$

In electroless plating, the coexistence of the reactants in the plating solution causes an intrinsic instability in the deposition process. A good deal of research has focused on finding good stabilizing agents, ${ }^{20}$ and in our research some nitrogen-containing heteroaromatic compounds that have been used as corrosion inhibitors were found to successfully improve reaction stability.

However, there is little research regarding the material properties of electroless deposited Ag films depending on the addition of such additives. It is known that heteroaromatic compounds with nitrogen atoms such as benzotriazole (BTA) adsorbed on copper surfaces and acted as corrosion inhibitors. ${ }^{21,22}$ In copper electroplating, BTA causes an increase in resistivity and randomizes the texture of the film. ${ }^{23} \mathrm{Ag}$ is also known to form a similar complex structure with heteroaromatic compounds. ${ }^{24}$ Therefore, the effects of stabilizing agents on film properties need to be intensively studied to obtain good-quality metal films.

In this research, we focus on the effects of the additives used for stabilizing film properties, in particular that of electrical conductivity and related film structures. Finally, we suggest a film growth model that explains the experimental results.

\section{Experimental}

The substrate, a TiN (chemical vapor deposited, $10 \mathrm{~nm}$ )/Ti (physical vapor deposited, $15 \mathrm{~nm}$ )/Si [p-type, (100)] structure, was treated in a $1 \%$ hydrofluoric acid (HF) solution for $10 \mathrm{~min}$ to remove native Ti oxide. ${ }^{25}$ For deposition of catalytic Pd clusters on the TiN surface, Pd activation was carried out by dipping the substrate for $20 \mathrm{~s}$ in a Pd activation solution. The Pd activation solution consisted of $0.56 \mathrm{mM} \mathrm{PdCl}_{2}, 29 \mathrm{mM} \mathrm{HCl}$, and $0.125 \mathrm{M} \mathrm{HF}$ in deionized water. ${ }^{25}$ The $\mathrm{Ag}$ electroless plating solution consisted of $4.5 \mathrm{mM} \quad \mathrm{AgNO}_{3}, 4.1 \mathrm{M} \mathrm{NH}_{4} \mathrm{OH}, 0.45 \mathrm{M}\left(\mathrm{NH}_{4}\right)_{2} \mathrm{SO}_{4}, 60 \mathrm{mM}$ $\mathrm{CoSO}_{4}, 90 \mathrm{mM}$ ethylenediamine, $45 \mathrm{mM}$ ethylenediaminetetraacetic acid, and stabilizing agents. The choice of stabilizing agent was

\footnotetext{
* Electrochemical Society Student Member.

** Electrochemical Society Active Member.

${ }^{\mathrm{z}}$ E-mail: jjkimm@snu.ac.kr
}

preceded by an observation of the in situ transmittance of the electrolyte using a He-Ne laser (Melles Griot, $632.8 \mathrm{~nm}$ ) and photodiode. The formation of large particles in an electrolyte scattered laser beam and the change of intensity were recorded using a data acquisition (DAQ) board (Keithley KPCI-3102). The decrease in intensity was qualitatively regarded as the degree of particle formation in the electrolyte. All deposition experiments were conducted at room temperature. Sheet resistances of the deposited films were measured by a four-point probe. Self-annealing was checked through sheetresistance changes. Film thickness and surface morphology were observed with field-emission scanning electron microscopy (FESEM) (Philips XL-30). Crystallinity and the depth profile of the film composition were analyzed by X-ray diffraction (XRD) and Auger electron spectroscopy (AES, Perkin-Elmer model I660), respectively. Grain sizes were calculated from XRD data using the Scherrer equation. The Ag films were annealed to decrease their resistivity in nitrogen ambient using a horizontal quartz tube furnace.

\section{Results and Discussion}

Figure 1 shows the in situ transmittance of Ag electroless plating solution with various additives. BTA, 5-aminotetrazole (ATRA), and 3-amino-1,2,4-triazole worked excellently as stabilizing agents of the Ag electroless plating solution. A stiff decrease in transmittance without any additive occurred due to the homogeneous reaction in the electrolyte between $\mathrm{Ag}$ ions and the reducing agent.

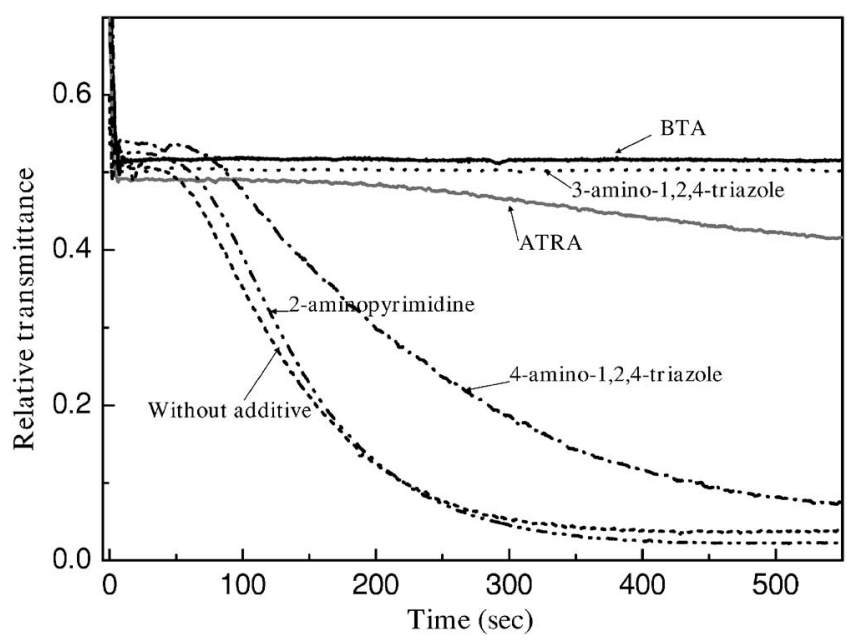

Figure 1. Transmittance of the electroless plating solution with various additives. The concentration of additives was $10 \mathrm{mM}$. 


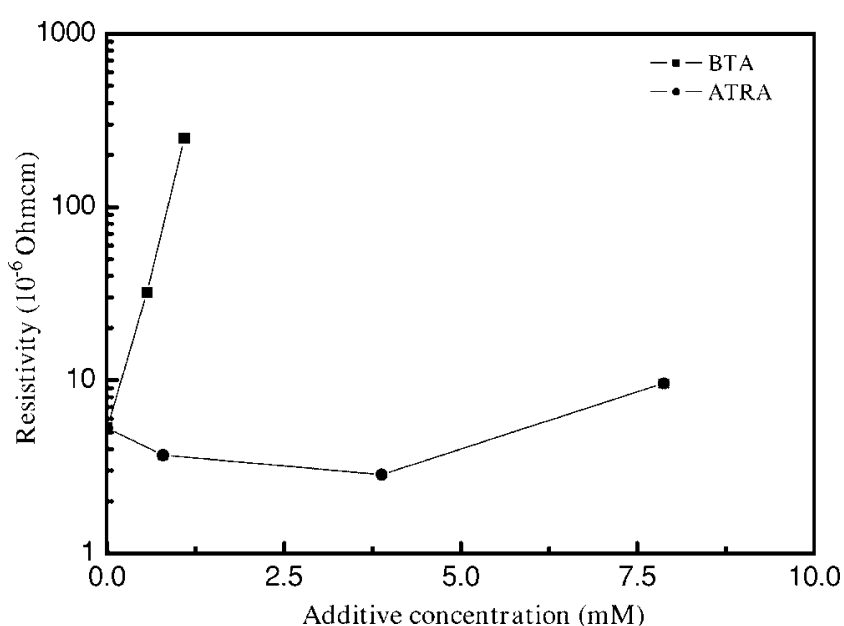

Figure 2. Changes of sheet resistance and resistivity according to additive concentration.

The changes in resistivity of the Ag films with respect to additive concentration are plotted in Fig. 2, and it shows that an increase of BTA concentration in the electroless plating solution resulted in a dramatic increase in resistivity. Furthermore, the resistivity was several tens of times larger than the bulk resistivity of $\mathrm{Ag}(1.59 \mu \Omega \mathrm{cm}$ at room temperature). Compared to BTA, the addition of ATRA did not considerably increase the resistivity that was closer to that of bulk Ag. The optimum concentrations of ATRA for obtaining the lowest film resistivity existed in the Ag electrolyte composition used, while the addition of BTA just increased film resistivity. An optimum additive concentration was obtained through comparing film roughness. All subsequent experiments with the additives used $3.9 \mathrm{mM}$ ATRA and $0.67 \mathrm{mM}$ BTA.

Surface morphologies of Ag films with stabilizing agents are shown in Fig. 3. The addition of ATRA and 3-amino-1,2,4-triazole induced smooth surface morphologies, which showed no significant difference compared to the nonadditive case, while the addition of BTA made distinct grains.

Interestingly, the sheet resistance of the Ag film with BTA decreased stiffly with elapsed time at room temperature as shown in Fig. 4. The total decrease of sheet resistance was about $60 \%$ from its as-deposited value. As a comparison, an Ag film without additives showed only a $4 \%$ decrease of sheet resistance after $10 \mathrm{~h}$, and there
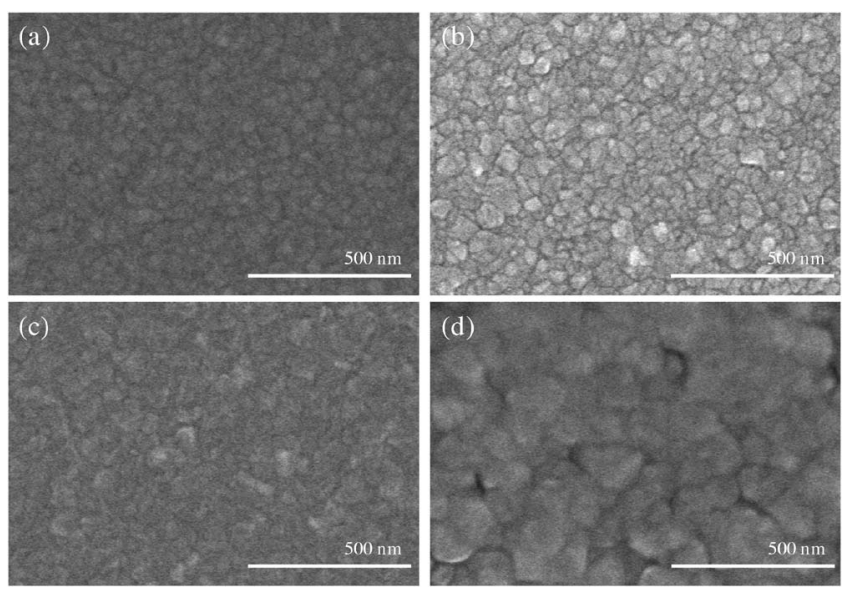

Figure 3. Surface morphologies of electrolessly deposited Ag films with various additives after $10 \mathrm{~min}$ deposition: (a) without additives, (b) with $0.67 \mathrm{mM}$ of BTA, (c) with $3.9 \mathrm{mM}$ of ATRA, and (d) with $0.3 \mathrm{mM}$ of 3-amino-1,2,4-triazole.

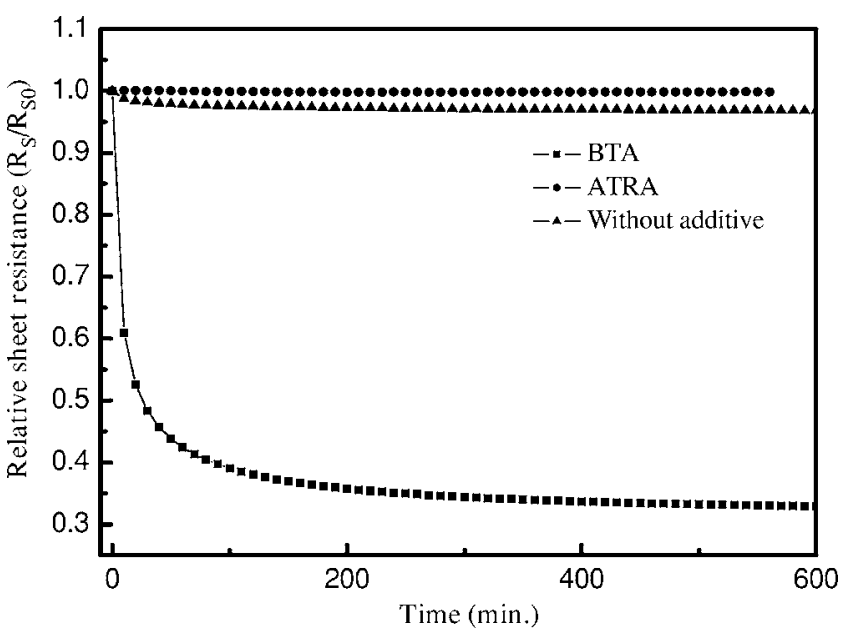

Figure 4. Sheet-resistance changes of Ag films with respect to elapsed time at room temperature.

was a negligible sheet-resistance change with ATRA. Considering the self-annealing effect in electroless plating, ${ }^{26,27}$ the experimental results suggest that the addition of BTA had a significant effect on the Ag film properties, that is, the thermal stability of the highly resistive structure was poor. The activation energy required to decrease resistivity is quite small and is easily obtained at room temperature. Furthermore, the high resistivity of the Ag film with BTA, which was decreased by self-annealing, showed a further decrease by annealing at $200^{\circ} \mathrm{C}$ for $30 \mathrm{~min}$. As shown in Fig. 5, there were significant differences in the changes of sheet resistance by annealing with the additives. The decrease ratio was over $80 \%$ with BTA, while in the case of ATRA the decrease ratio was about $25 \%$ in thin films, and the ratio decreased further as film thickness increased.

The changes of the XRD data of Ag films with a thickness of approximately $60 \mathrm{~nm}$ according to the additives and annealing are depicted in Fig. 6. Figure 7 shows grain sizes calculated from XRD data and the resistivity of $\mathrm{Ag}$ films as a function of thickness with various additives. Remarkably, the as-deposited film with BTA showed quite different properties compared to those both with ATRA and without additives. In the case of BTA, the (111) peak intensity was relatively weak compared to the other cases and in-

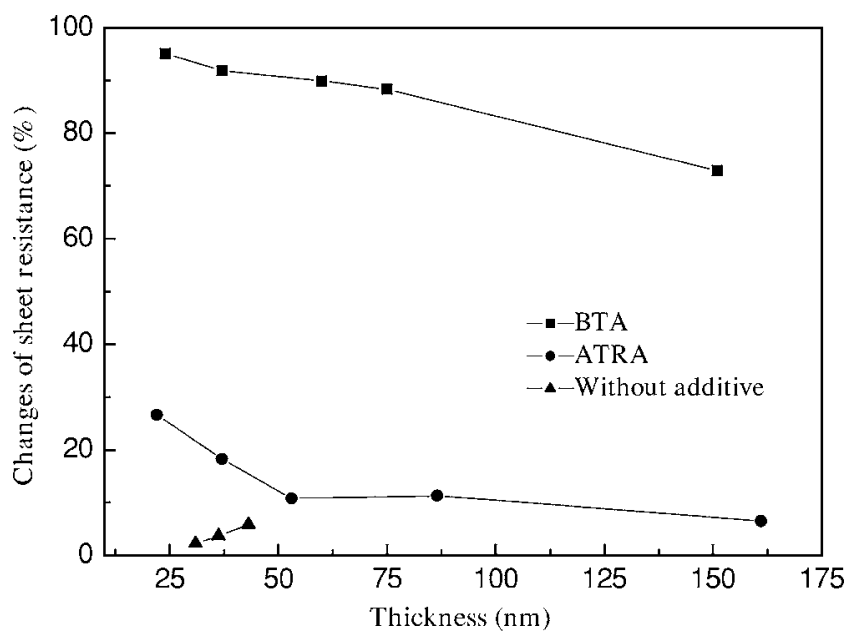

Figure 5. Sheet-resistance changes of Ag films according to the additives after annealing at $200^{\circ} \mathrm{C}$ for $30 \mathrm{~min}$ in nitrogen ambient as the film thickness. The square symbols represent the samples with $0.67 \mathrm{mM}$ of BTA, the circular symbols are the samples with $3.9 \mathrm{mM}$ of ATRA, and the triangle symbols are the samples without additives. 


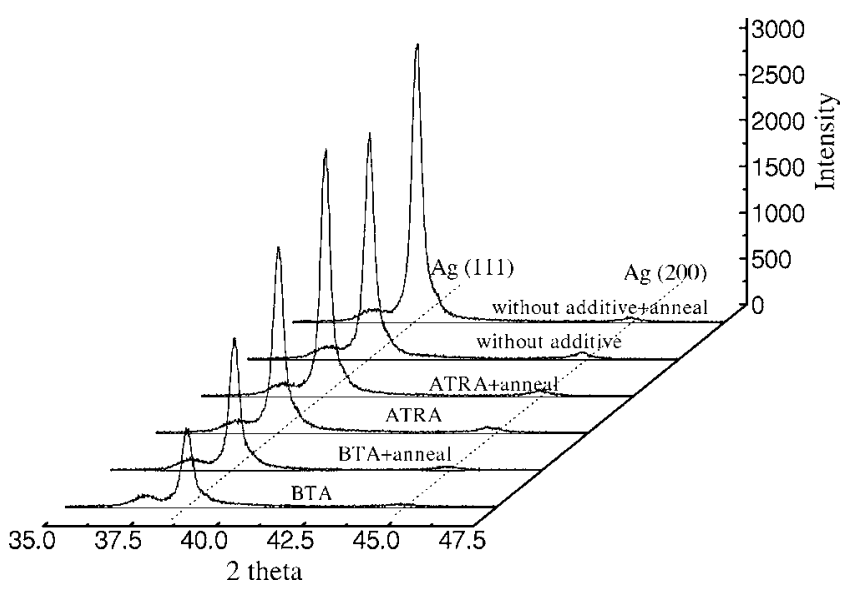

Figure 6. XRD data of Ag films before and after annealing according to the additives.

creased substantially after annealing. The peak intensity of Ag film with ATRA also increased after annealing but was comparable to the case without additives. The ratio of peak intensity between (111) and (200) was higher than 20 in the case of BTA, whereas without additives after annealing, the ratio was over 100 . The $\mathrm{Ag}$ film without additives had a larger grain compared to the other cases with additives of the same thickness, which may be a result of cluster-growth inhibition at the initial stage of the electroless plating due to catalyst deactivation by the adsorption of additives. The grain sizes of all films were increased 10-20\% after annealing regardless of the additives. Therefore, the grain growth in BTA during annealing was not sufficient for explaining the sudden decrease in resistivity after annealing. The film-resistivity values decreased slightly in all cases while thickness increased, and a similar relation between resistivity and thickness after annealing was observed regardless of additives. The lowest resistivity of the $90 \mathrm{~nm}$ Ag film with $3.9 \mathrm{mM}$ of ATRA was $3.4 \mu \Omega \mathrm{cm}$ before annealing, which decreased to $3.0 \mu \Omega \mathrm{cm}$ after annealing in $200^{\circ} \mathrm{C}$ for $30 \mathrm{~min}$. Although the $75 \mathrm{~nm} \mathrm{Ag}$ film with BTA showed a resistivity higher than $30 \mu \Omega \mathrm{cm}$, annealing at the same conditions reduced the resistivity to $4.0 \mu \Omega \mathrm{cm}$. The results of AES analysis of the film with BTA before and after annealing, shown in Fig. 8, also revealed that no impurities were incorporated. It showed that the existence of impurities and their redistribution were not the reason for the high resistivity of the as-deposited film with BTA.

The thickness dependence of the resistivity was analyzed using the Mayadas-Shatzkes model. ${ }^{28}$ The fitting of the resistivity data by a simplified equation of the thin-film resistivity model was attempted. The simplified model equation of the film resistivity considered surface and grain-boundary scattering as shown below ${ }^{29}$

$$
\begin{aligned}
& \rho_{\mathrm{s}}=\rho_{0}\left[1+\frac{3 \lambda}{8 t}(1-p)\right] \quad(\text { surface scattering }) \\
& \rho_{\mathrm{g}}=\rho_{0}\left[1-\frac{3}{2} \alpha+3 \alpha^{2}-3 \alpha^{3} \ln \left(1+\frac{1}{\alpha}\right)\right]^{-1}
\end{aligned}
$$

(grain-boundary scattering)

$$
\alpha=\frac{\lambda}{d} \frac{R}{1-R}
$$

where $\rho_{0}$ represents bulk resistivity, $t$ represents film thickness, $p$ represents the scattering coefficient, $\lambda$ represents the surface, meanfree path of electrons in bulk $\mathrm{Ag}, d$ represents the grain size, and $R$ represents the grain-boundary scattering coefficient of electrons. Adequate fitting parameters of the film-resistivity data after annealing were $\rho_{0}=1.6 \mu \Omega \mathrm{cm}, R=0.24, p=0.05$, and $\lambda=57 \mathrm{~nm} \cdot{ }^{30} \mathrm{In}$ this
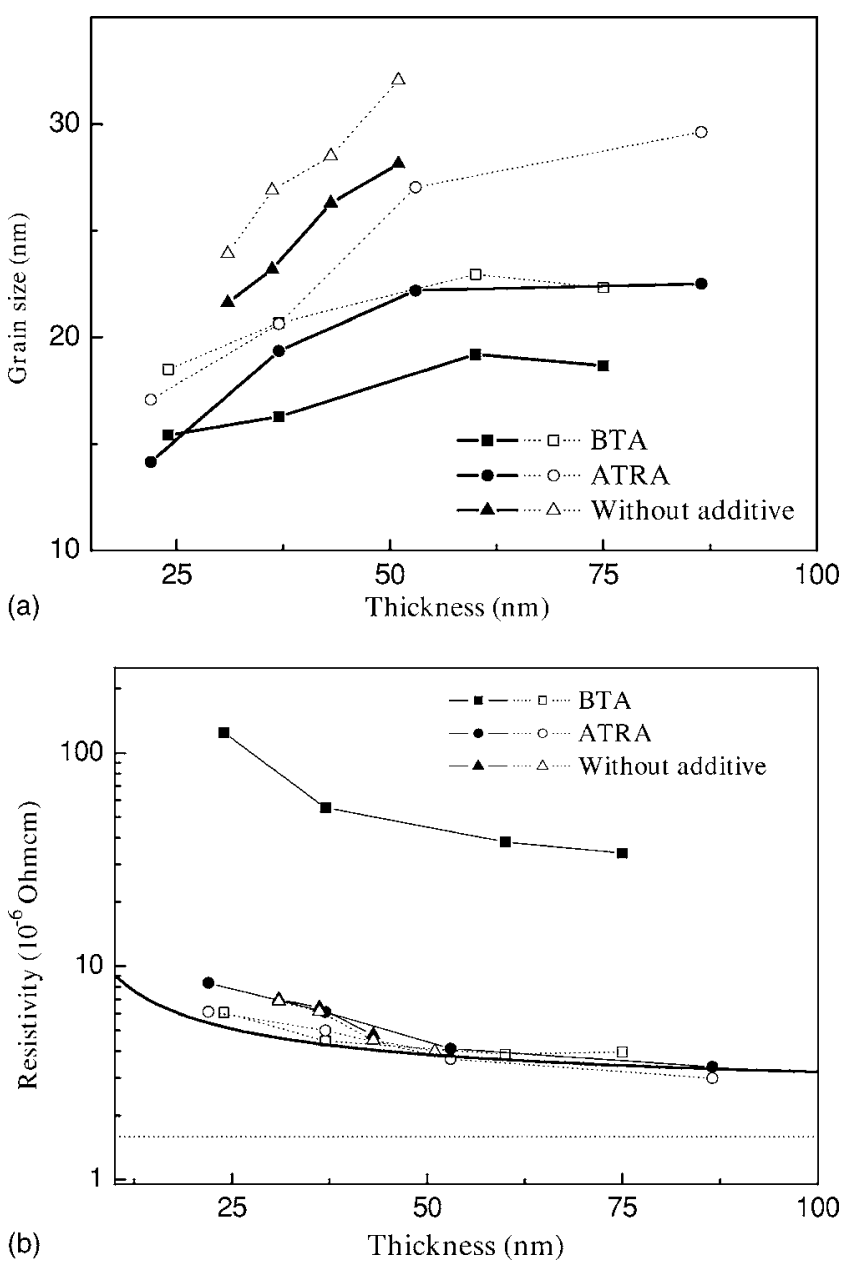

Figure 7. (a) Relations between grain sizes and film thicknesses and (b) relations between film thicknesses and resistivities according to the additives before and after annealing at $200^{\circ} \mathrm{C}$ in a $\mathrm{N}_{2}$ ambient for $30 \mathrm{~min}$. The solid and open symbols represent before and after annealing, respectively. The bold solid line in (b) represents the relationship between the thickness and resistivity of the metal film expected by the Mayadas-Shatzkes model with a bulk resistivity at 1.6 , a reflection coefficient at 0.24 , a surface scattering coefficient at 0.05 , a mean-free path of electrons at $57 \mathrm{~nm}$, and average grain-thickness relations, which were measured in our experiments with ATRA.

calculation, the grain-thickness relation of the case with addition of ATRA before annealing was used. As the data set was roughly close to the average of the other data, it gave some representative expectation for the result. When the relation data of the BTA case before annealing were used, a slight change in the calculated result was observed. However, the difference was not so significant compared to the experimental result. However, it was hard to fit the resistivitythickness data to the BTA case before annealing. Abnormalities of the BTA data may originate from the relatively large roughness compared to the thickness at the initial stage of growth and the effect of the conductive substrate (TiN/Ti). Another reason may be the deviations of grain-size according to the thickness of the film. It was clear that a value of at least 0.7 or higher for the grain-boundary scattering coefficient was required for fitting the experimental data with BTA before annealing.

In $\mathrm{Cu}$ electroplating, an increase in resistivity also occurred through the addition of BTA, followed by a significant decrease in resistivity after annealing. ${ }^{23}$ In that case, a weak $\mathrm{Cu}(111)$ texture was a clue of small and randomized grains, which are the main reason for the high resistivity of $\mathrm{Cu}^{23}$ This does not explain the full phenomena in Ag electroless plating with BTA. Here, it may be due 

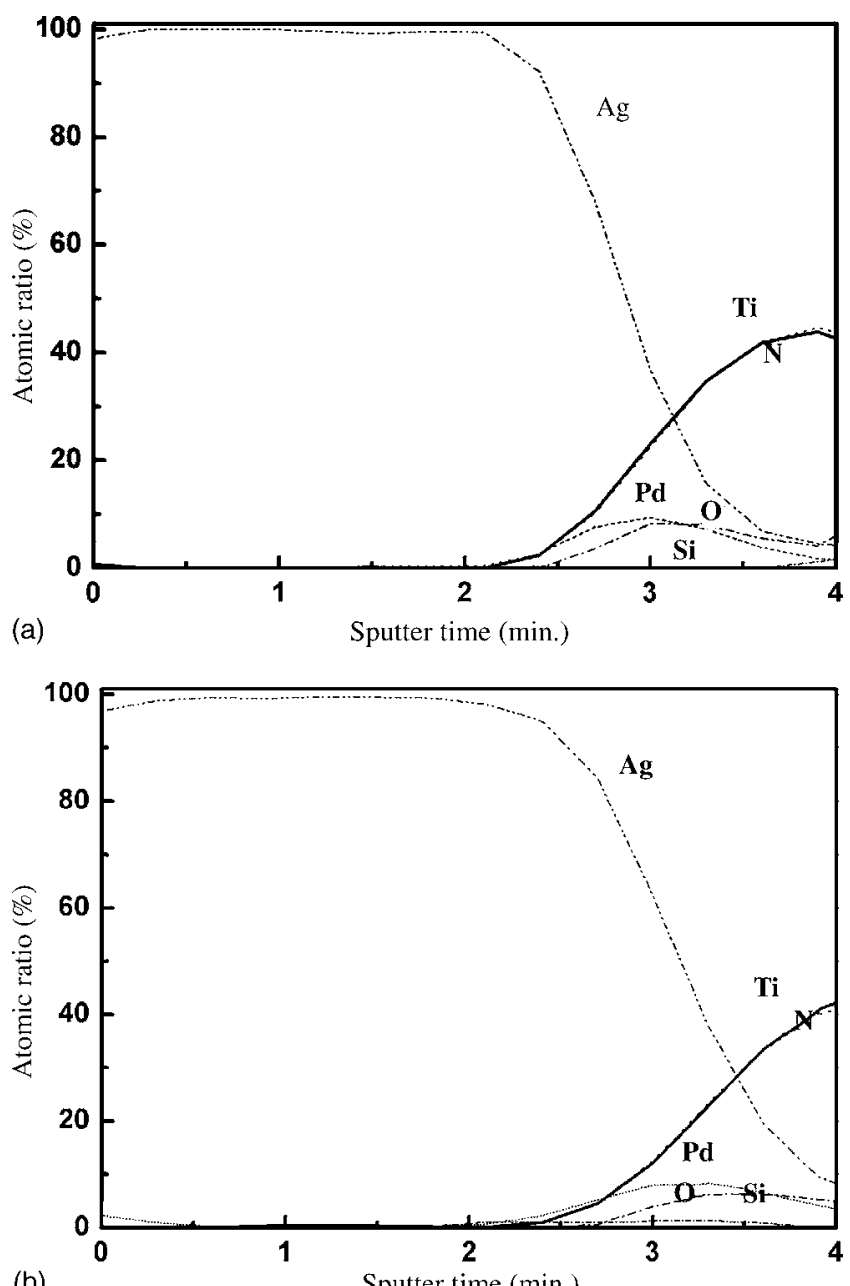

(b)

Sputter time (min.)

Figure 8. AES depth profiles of the Ag film with BTA (a) before and (b) after annealing at $200^{\circ} \mathrm{C}$ in nitrogen ambient for $30 \mathrm{~min}$.

to Pd activation because the Ag nucleation density was fully controlled by Pd clusters, while in $\mathrm{Cu}$ electroless plating the nucleation density was strongly affected by the adsorption of additives. Ag grains on each Pd cluster grew to fill the space between the Pd clusters without any spatial limitation in Ag electroless plating because electroless plating took place only on the catalytic Pd surface, and the catalytic activity of Pd clusters was not strongly inhibited by the additives, which explained the initial stages of electroless plating

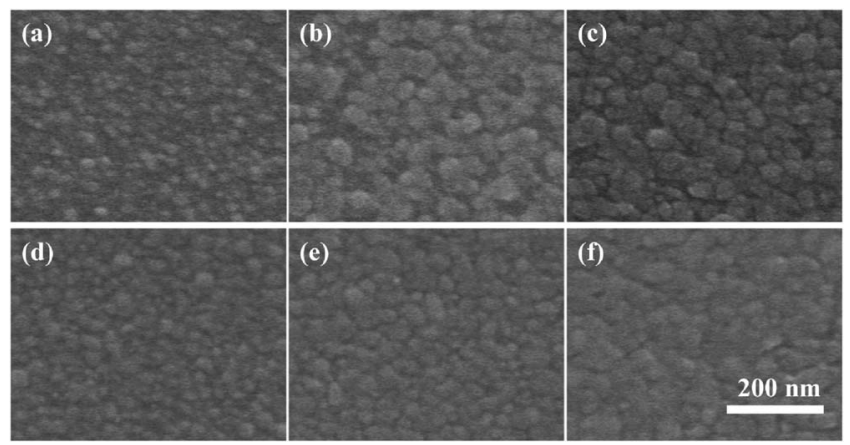

Figure 9. FESEM images of the initial stages of film growth in Ag electroless plating with BTA (a) after $10 \mathrm{~s}$, (b) after $30 \mathrm{~s}$, and (c) after $60 \mathrm{~s}$ and without additives (d) after $10 \mathrm{~s}$, (e) after $30 \mathrm{~s}$, and (f) after $60 \mathrm{~s}$ deposition. according to the additives in Fig. 9. There were no significant differences in grain boundaries due to the addition of BTA after $10 \mathrm{~s}$ deposition. However, after $60 \mathrm{~s}$ deposition, clear boundaries were observed when BTA was added, while there were still no clear boundaries without additives. This suggested that the major effect of BTA addition was the interruption of contact of conductive grain boundaries through inhibiting grain coalescence. Similar phenomena are reported in $\mathrm{Ag}-\mathrm{W}$ electroless plating with hydrazine by incorporating tungsten oxides at the grain boundaries. ${ }^{17}$ Even though the amount of incorporated additives was small (under the detection limit of AES) and was concentrated on the local area such as grain boundary or surface, the surface character of the BTA-adsorbed metal film could be completely changed. Adsorption and incorporation of additives at the grain boundary could be a major reason for the highly resistive layer. However, it was not enough to explain the difference between BTA and other cases. Considering some complex interactions between adsorbed additives and electroless plating reactions, the molecular structure and related hydrophilicity of BTA and ATRA were related to the differences in Ag-film properties. In the case of $\mathrm{Cu}$, formation of the $\mathrm{Cu}(\mathrm{I})$-BTA complex film structure and adsorption of it with high surface coverage made the metal surface hydrophobic, ${ }^{31}$ while the amino group of ATRA acted as a hydrophilic tail, in spite of a similar adsorption mechanism. ${ }^{22,32}$ Two additives gave quite different macroscopic surface characters after film growth. With BTA, the surface was hydrophobic, whereas the addition of the ATRA surface showed wetting properties similar to the case without the additive. From the microscopic point of view, the formation of significant grooves on the Ag film with BTA may originate from the high surface energy at the zipping moment of the three-dimensional (3D) clusters. In contrast, with ATRA the space between grain boundaries may be easily filled by newly deposited $\mathrm{Ag}$ to decrease the total surface energy, leading to a conductive $\mathrm{Ag}$ film. Therefore, even though the addition of ATRA moderately affected the grain size, peak intensity, and resistivity as shown in previous results, the electrical characteristics of the grain boundaries were quite different from the BTA case. This postulate could be applied to other additives, such as 3-amino-1,2,4-triazole, which also has an amino group and successive stabilizing performance without increasing the resistivity of the Ag film. The film's surface was hydrophilic, as was the case with ATRA, and microscopically there were no significant grooves.

A summary of the suggested growth mode of Ag electroless plating is shown in Fig. 10. At the moment of coalescence in the growing Ag clusters on discontinuous catalytic Pd clusters (Fig. 10a), the formation of the grain-boundary structure is different due to the adsorbed additives and surface character of the clusters. Furthermore, it is difficult to obtain two-dimensional growth of Ag (Fig. 10b) due to the high surface energy between the TiN substrate and growing Ag clusters. ${ }^{33}$ With the low deposition temperature of electroless plating, there may be no significant atomic motion or rearrangement during the deposition process, and the grain size may be limited due to the similar scale of density of the Pd clusters. As shown in Fig. 10c, a highly resistive grain-boundary structure may be formed during the agglomeration of the growing 3D clusters when the surface is covered with additives that make the surface hydrophobic. Low-resistance Ag grains were electrically isolated from each other in spite of a physical connection in the microscopic view, and therefore the Ag film with BTA shows high resistivity. As the highly resistive zone in the film structure may include nanoscale voids or incorporated additive molecules, the conductivity through it was relatively low and easily rearranged by thermal annealing at low temperatures. ${ }^{17}$ The density of the Pd clusters deposited on the TiN substrate was about $10^{3}$ particles $/ \mu \mathrm{m}^{2}$, and its corresponding grain size was about $30 \mathrm{~nm}$, which is close to the value of the measured grain sizes from XRD. The instability of the highly resistive boundary structure resulted in a sudden decrease in resistivity by annealing, and as a result, a similar structure can be obtained regardless of the additives, as shown in Fig. 10d. 


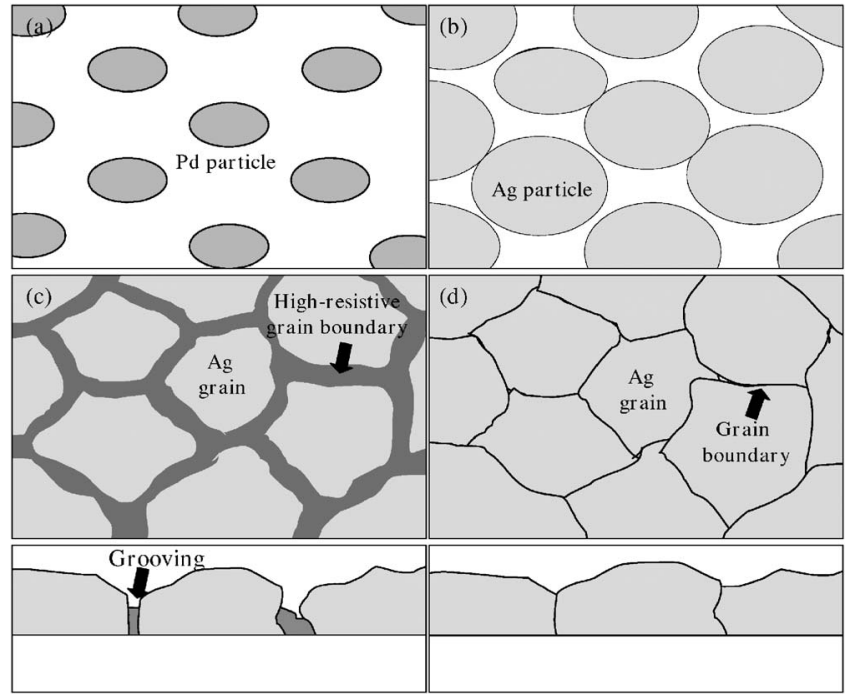

Figure 10. Schematic diagrams of Ag film growth by electroless deposition on a Pd-activated substrate: (a) after Pd activation, (b) before coalescence, (c) after formation of a continuous film with the addition of BTA, containing highly resistive grain boundaries, (d) after the formation of a continuous film containing low resistive boundaries with other additives or thermal annealing. The dark gray circle in (a) represents Pd clusters deposited by Pd activation, the light gray circles in (b) are Ag particles growing on Pd clusters, the dark and thick lines in (c) are highly resistive grain boundaries, and the thin black line in (d) are low-resistive grain boundaries.

\section{Conclusion}

The effects of stabilizing agents, especially BTA, on the electrical properties of electroless deposited Ag films were analyzed. The addition of BTA significantly increased the resistivity of the Ag film even though it had continuous film morphology and no detectable impurities. With ATRA, the electrolyte had enough stability and resulted in the low-resistance Ag film. With the addition of BTA, a sudden decrease in resistivity occurred during the annealing process without significant changes in film composition or grain size. It is suspected that the reason for the high resistivity of the film without BTA and the sharp decrease during annealing was the significant scattering of the electrons at the grain boundaries. Combined with the hydrophobic character of the BTA-adsorbed surface, thermally unstable and highly resistive grain boundaries are generated at the moment of coalescence of the clusters and make an abnormally high resistance $\mathrm{Ag}$ film with a dramatic decrease in resistivity after annealing.

\section{Acknowledgments}

This work was supported by the Korea Science and Engineering Foundation through the Research Center for Energy Conversion and Storage.

Seoul National University assisted in meeting the publication costs of this article.

\section{References}

1. P. C. Andricacos, C. Uzoh, J. O. Dukovic, J. Horkans, and H. Deligianni, IBM J. Res. Dev., 42, 567 (1998).

2. V. M. Dubin, Y. Shacham-Diamand, B. Zhao, and P. K. Vasudev, J. Electrochem. Soc., 144, 898 (1997).

3. C. H. Lee, S. K. Cho, and J. J. Kim, Electrochem. Solid-State Lett., 8, J27 (2005)

4. C. H. Lee, S. C. Lee, and J. J. Kim, Electrochem. Solid-State Lett., 8, C110 (2005).

5. Z. Wang, O. Yaegashi, H. Sakaue, T. Takahagi, and S. Shingubara, J. Electrochem. Soc., 151, C781 (2004).

6. J. J. Kim, S.-K. Kim, C. H. Lee, and Y. S. Kim, J. Vac. Sci. Technol. B, 21, 33 (2003)

7. S.-K. Kim, S. K. Cho, J. J. Kim, and Y.-S. Lee, Electrochem. Solid-State Lett., 8, C19 (2005).

8. Z. Wang, S. Shingubara, H. Sakaue, and T. Takahaqi, J. Electrochem. Soc., 152, C684 (2005).

9. T. Osaka, N. Takano, T. Kurokawa, T. Keneko, and K. Ueno, J. Electrochem. Soc., 149, C573 (2002).

10. Y. Shacham-Diamand, A. Zylberman, N. Petrov, and Y. Sverdlov, Microelectron. Eng., 64, 315 (2002)

11. A. Kohn, M. Eisenberg, and Y. Shacham-Diamand, J. Appl. Phys., 94, 3015 (2003).

12. C.-K. Hu, L. Gignac, R. Rosenberg, E. Liniger, J. Rubino, C. Sambucetti, A Domenicucci, X. Chen, and A. K. Stamper, Appl. Phys. Lett., 81, 1782 (2002).

13. T. Osaka, N. Takano, T. Kurokawa, T. Kaneko, and K. Ueno, Surf. Coat. Technol., 169-170, 124 (2003).

14. H. Einati, V. Bogush, Y. Sverdlov, Y. Rosenberg, and Y. Shacham-Diamand, $M i$ croelectron. Eng., 82, 623 (2005)

15. H. Nakano, T. Itabashi, and H. Akahoshi, J. Electrochem. Soc., 152, C163 (2005).

16. A. Inberg, Y. Shacham-Diamand, E. Rabinovich, G. Golan, and N. Croitoru, Thin Solid Films, 389, 213 (2001).

17. V. Bogush, A. Inberg, N. Croitoru, V. Dubin, and Y. Shacham-Diamand, Thin Solid Films, 426, 288 (2003).

18. H. Tong, L. Zhu, M. Li, and C. Wang, Electrochim. Acta, 48, 2473 (2003).

19. S. H. Cha, H.-C. Koo, and J. J. Kim, J. Electrochem. Soc., 152, C388 (2005).

20. G. O. Mallory, in Electroless Plating: Fundamentals and Applications, G. O. Mallory and J. B. Hajdu, Editors, American Electroplaters and Surface Finishing Society, New York (1996).

21. R. Subramanian and V. Lakshiminarayanan, Corros. Sci., 44, 535 (2002).

22. J.-W. Lee, M.-C. Kang, and J. J. Kim, J. Electrochem. Soc., 152, C827 (2005).

23. J. J. Kim, S.-K. Kim, and J.-U. Bae, Thin Solid Films, 415, 101 (2002).

24. S. Naumov, S. Kapoor, S. Thomas, S. Venkateswaran, and T. Mukherjee, J. Mol. Struct.: THEOCHEM, 685, 127 (2004).

25. J. J. Kim and S. H. Cha, Jpn. J. Appl. Phys., Part 1, 40, 7151 (2001).

26. C. H. Lee and J. J. Kim, J. Vac. Sci. Technol. B, 22, 180 (2004)

27. C. H. Lee and J. J. Kim, J. Vac. Sci. Technol. B, 23, 475 (2004).

28. A. F. Mayadas and M. Shatzkes, Phys. Rev. B, 1, 1382 (1970).

29. J.-W. Lim, K. Mimura, and M. Isshiki, Appl. Surf. Sci., 217, 95 (2003)

30. D. Jossel, C. Burkhard, Y. Li, Y.-W. Cheng, R. R. Keller, C. A. Witt, D. R. Kelley, J. E. Bonevich, B. C. Baker, and T. P. Moffat, J. Appl. Phys., 96, 759 (2004).

31. P.-L. Chen, J.-H. Chen, M.-S. Tsai, B.-T. Dai, and C.-F. Yeh, Microelectron. Eng., 75, 352 (2004).

32. H. Niino and A. Yabe, Appl. Phys. Lett, 63, 3527 (1993).

33. P. Xiao and B. Derby, Acta Mater., 44, 307 (1996). 